\title{
EFFECTIVENESS OF HOME BLEACHING AGENTS IN DISCOLORED TEETH AND INFLUENCE ON ENAMEL MICROHARDNESS
}

\author{
Carina Sinclér DELFINO ${ }^{1}$, Michelle Alexandra CHINELATTI ${ }^{2}$, Laíse Daniela CARRASCO-GUERISOLI ${ }^{1}$, Andrigo Reis BATISTA ${ }^{3}$, \\ Izabel Cristina FRÖNER ${ }^{4}$, Regina Guenka PALMA-DIBB ${ }^{5}$
}

\author{
1- DDS, MSc, Graduate student, Department of Restorative Dentistry, Ribeirão Preto Dental School, University of São Paulo, Ribeirão Preto, SP, \\ Brazil. \\ 2- DDS, MSc, PhD, Lab Technician, Department of Restorative Dentistry, Ribeirão Preto Dental School, University of São Paulo, Ribeirão Preto, SP, \\ Brazil. \\ 3- Undergraduate student, Department of Restorative Dentistry, Ribeirão Preto Dental School, University of São Paulo, Ribeirão Preto, SP, Brazil. \\ 4- DDS, MSc, PhD, Associate Professor of Endodontics, Department of Restorative Dentistry, Ribeirão Preto Dental School, University of São Paulo, \\ Ribeirão Preto, SP, Brazil. \\ 5- DDS, MSc, PhD, Associate Professor of Restorative Dentistry, Department of Restorative Dentistry, Ribeirão Preto Dental School, University of São \\ Paulo, Ribeirão Preto, SP, Brazil.
}

Corresponding address: Profa. Dra. Regina Guenka Palma-Dibb - Faculdade de Odontologia de Ribeirão Preto - USP - Departamento de Odontologia Restauradora - Av. do Café, s/nº. CEP: 14040-904. Ribeirão Preto - SP. Brazil - Phone: 55-16-3602-4016 - Fax: 55-16-3633-0999 - e-mail: rgpalma@forp.usp.br

Received: August 26, 2008 - Modification: November 10, 2008 - Accepted: November 30, 2008

\begin{abstract}
$O$

bjectives: This study evaluated the effectiveness of different home bleaching agents on color alteration and their influence on surface and subsurface microhardness of discolored bovine enamel. Material and Methods: Forty-five fragments of bovine incisors were randomly allocated into 3 groups $(\mathrm{n}=15)$ according to the bleaching agent: $10 \%$ carbamide peroxide gel (CP10), 16\% carbamide peroxide gel (CP16) and 6.5\%-hydrogen-peroxide-based strip (HP6.5). Before bleaching treatment, initial values of Knoop surface microhardness and color (CIEL*a* $\mathrm{b}^{*}$ ) were obtained and the fragments were artificially stained in hemolyzed rat blood. Then, bleaching treatments were performed over a 21 -day period. Color changes $(\Delta \mathrm{E})$ were assessed at 7,14 and 21 days, and final surface microhardness reading was done after 21 days. Thereafter, the fragments were bisected to obtain subsurface microhardness. Data were subjected to ANOVA and Tukey's tests $(\alpha=5 \%)$. Results: Color changes produced by CP16 were similar to those of CP10, and the color changes produced by these materials were significantly superior to those produced by HP6.5. Color changes at 21 days were superior to 7 days and similar to 14 days. The time did not influence color changes for CP16, which showed similarity between the 14- and 21-day results. No statistically significant differences were found among the home bleaching agents for surface and subsurface microhardness. Conclusions: Microhardness of bovine enamel was not affected by the bleaching agents. The $16 \%$ carbamide peroxide gel was the most effective for bleaching the stained substrate.
\end{abstract}

Key words: Tooth bleaching. Dental enamel. Microhardness. Color change, CIEL*a*b*.

\section{INTRODUCTION}

Tooth color is currently believed to be one of the most important esthetic concerns for patients ${ }^{1}$. Vital tooth bleaching has widely been performed, and several materials and techniques have been presented for this purpose ${ }^{16}$. Vital tooth bleaching is considered a safe, effective, minimally invasive, non-destructive and well-accepted procedure for the treatment of discolored teeth ${ }^{27,29}$.

A number of methods and approaches have been described for the bleaching of vital teeth ${ }^{17}$. However, basically, there are three techniques: in-office or power bleaching, mass market bleaching products, and dentist- supervised home bleaching ${ }^{15}$. Since its introduction by Haywood and Heymann ${ }^{14}$ (1989), several products have been employed for home bleaching. These products are mainly available in gels or strips containing several concentrations of carbamide peroxide or hydrogen peroxide ${ }^{29}$. Carbamide peroxide gel at a $10 \%$ concentration is one of the most commonly employed home bleaching agents due to its safety and effectiveness ${ }^{12}$. Although different concentrations of carbamide and hydrogen peroxides have shown similar results ${ }^{10,18,29}$, increased concentrations and application times may cause enamel surface alterations, such as loss of mineral content and microhardness ${ }^{2,22}$.

Thus, considering the divergences on the effects of 
bleaching agents on properties of hard tooth tissues, the purposes of this study were to evaluate the effectiveness of different home bleaching agents and their effects on surface and subsurface microhardness of bovine enamel. The hypotheses tested in this study were that the type of bleaching agent influences the color alteration in stained teeth, but does not influence the surface and subsurface microhardness of bovine enamel.

\section{MATERIAL AND METHODS}

\section{Enamel Specimen Preparation}

Forty-five freshly extracted sound bovine incisors were selected and stored under refrigeration in a saturated thymol solution until preparation for testing. Teeth had their roots removed $2 \mathrm{~mm}$ apically to the cementoenamel junction in a sectioning machine with a water-cooled diamond saw (Minitom, Struers A/S, Copenhagen, D2610, Denmark). The buccal surfaces of the crowns were cut longitudinally and transversely, using double-faced diamond discs mounted at a low-speed handpiece in order to obtain fragments with dimensions of $11 \mathrm{~mm}$ x $11 \mathrm{~mm}$. To obtain plane surfaces, required for microhardness tests, the external enamel surfaces of the fragments were flattened in a water-cooled polishing machine (Politriz; Struers A/S) using 600-, 1000and 1200-grit silicon carbide abrasive papers sequentially, followed by a final polishing with a $0.3-\mu \mathrm{m}$-gamma alumina suspension on felt wheel. The specimens were kept in an ultrasonic bath (Sonic Clean, D.M.C. Equipamentos Ltda., São Carlos, SP, Brazil) in distilled and deionized water for $10 \mathrm{~min}$ to remove polishing debris.

\section{Staining Procedure}

Artificial staining of the specimens was performed following a modification ${ }^{5}$ of the method proposed by Freccia and Peters ${ }^{8}$. Blood samples collected from adult male Wistar rats (weighing 200 to $250 \mathrm{~g}$ ) were heparinised to avoid coagulation, and were centrifuged at $10,000 \mathrm{rpm}$ for $10 \mathrm{~min}$. The blood serum was discarded and $40 \mathrm{~mL}$ of distilled and deionized water were added to $60 \mathrm{~mL}$ of the precipitated blood. This mixture was centrifuged at 10,000 rpm for 20 min, resulting in a rich-haemoglobin hemolyzate blood solution. Specimens were immersed in this solution for 4 days, performing a centrifugation cycle (10,000 rpm, $20 \mathrm{~min})$ at every $24 \mathrm{~h}$. After 4 days, the specimens were removed, washed in distilled water, dried with absorbent paper and kept at $37^{\circ} \mathrm{C}$ in $100 \%$ relative humidity for 15 days.

\section{Bleaching Treatment}

After staining, the specimens were randomly assigned to 3 groups $(n=15)$ according to the bleaching treatment: $10 \%$ carbamide peroxide gel (CP10), 16\% carbamide peroxide gel (CP16) and 6.5\%-hydrogen-peroxide-based strip (HP6.5). The bleaching treatment was performed over 21 days, according to the manufacturers' instructions. Specifications of the materials used in this phase are given in Figure 1. For each specimen of the groups treated with the bleaching gels (CP10 and CP16), a tray was fabricated using a low-density polyethylene sheet and a vacuumthermoforming machine. Every day, a thin layer of each gel was applied on the enamel surface and the tray was placed on each specimen, which was stored for $8 \mathrm{~h}$ at $37^{\circ} \mathrm{C}$ in a recipient containing artificial saliva $(\mathrm{pH} 7.0$ - Figure 1). After $8 \mathrm{~h}$, the gel was removed from enamel surface with running distilled water for $15 \mathrm{~s}$.

Enamel surfaces of the group treated with the bleaching strip (HP6.5) were covered with the strip for 30 min twice a day. After each application, the strips were removed from enamel surfaces, which were rinsed with running distilled

\begin{tabular}{|c|c|c|}
\hline Bleaching agent & Composition & Manufacturer \\
\hline $\begin{array}{c}\text { CP10 } \\
\text { Opalescence Whitening Gel }\end{array}$ & $\begin{array}{c}\text { 10\% Carbamide Peroxide, Carbopol, Glycerin, } \\
\text { Flavoring }\end{array}$ & $\begin{array}{l}\text { Ultradent Products Inc., South } \\
\text { Jordan, Utah, USA }\end{array}$ \\
\hline $\begin{array}{l}\text { CP16 } \\
\text { Clarigel Gold 16\% }\end{array}$ & $\begin{array}{c}\text { Sodium Benzoate, EDTA, Carbopol, 16\% } \\
\text { Carbamide Peroxide, Sodium Fluoride, Mint } \\
\text { Flavor }\end{array}$ & $\begin{array}{l}\text { Dentsply Indústria e Comércio } \\
\text { Ltda, Petrópolis, RJ, Brazil }\end{array}$ \\
\hline $\begin{array}{c}\text { HP6.5 } \\
\text { Crest Whitestrips Classic }\end{array}$ & $\begin{array}{c}\text { Purified Water, Glycerin, 6.5\% Hydrogen } \\
\text { Peroxide, Carbopol, Sodium Hydroxide, } \\
\text { Sodium Acid Pyrophosphate, Sodium Stannate }\end{array}$ & $\begin{array}{l}\text { Procter \& Gamble Company, } \\
\text { Cincinnati, Ohio, USA }\end{array}$ \\
\hline Artificial saliva & $\begin{array}{c}\mathrm{K}_{2} \mathrm{HPO}_{4}, 70 \% \text { Sorbitol, NaF, } \mathrm{KCl}, \mathrm{NaCl} \\
\mathrm{MgCl}_{2} \cdot 6 \mathrm{H}_{2} \mathrm{O}, \mathrm{CaCl}_{2} \cdot 2 \mathrm{H}_{2} \mathrm{O} \text {, Nipagin, Sodium } \\
\text { Benzoate, Hydroxyethylcellulose }\end{array}$ & $\begin{array}{l}\text { Department of Biochemistry, } \\
\text { School of Pharmaceutical } \\
\text { Sciences of Ribeirão Preto, } \\
\text { University of São Paulo, } \\
\text { Ribeirão Preto, SP, Brazil }\end{array}$ \\
\hline
\end{tabular}

FIGURE 1- Materials employed 
water for $15 \mathrm{~s}$.

In all groups, when the specimens were not in contact with the bleaching agents, they were kept at $37^{\circ} \mathrm{C}$ immersed in artificial saliva, which was changed daily.

\section{Color Measurement}

The color of the specimens was measured after the artificial staining (baseline) and 7, 14 and 21 days after the beginning of the bleaching treatment. Before each color measurement, specimens were rinsed with water and dried with absorbent paper. Color was measured over a white background employing a color spectrophotometer (Color guide 45/0, PCB 6807; BYK-Gardner, GmbH Gerestsried, Germany), which records the color variables $L^{*}, a^{*}, b^{*}$ according to the CIEL*a*b* (Commission Internationale de l'Eclairage $\left.L^{*}, a^{*}, b^{*}\right)$ color system ${ }^{18}$, where $\mathrm{L}^{*}$ stands for luminosity dimension or whiteness, ranging from 0 (pure black) to 100 (reference white), a* for green-red contrast ($\mathrm{a}^{*}=$ green and $+\mathrm{a}^{*}=$ red) and $\mathrm{b}^{*}$ for blue-yellow contrast $(-$ $\mathrm{b}^{*}=$ blue and $+\mathrm{b}^{*}=$ yellow $)$. Color change $(\Delta \mathrm{E})$ was calculated from $\mathrm{L}^{*}, \mathrm{a}^{*}$ and $\mathrm{b}^{*}$ values employing the following formula: $\Delta E=\left[\left(\Delta L^{*}\right)^{2}+\left(\Delta a^{*}\right)^{2}+\left(\Delta b^{*}\right)^{2}\right]^{1 / 2}$. Positive $\Delta \mathrm{L}^{*}$ means the specimens became whiter, while negative $\Delta \mathrm{L}^{*}$ means specimens became darker.

\section{Microhardness Testing}

Knoop microhardness measurements of the enamel surface were performed before the staining procedure (initial values) and following the bleaching treatment (after 21 days) using a microhardness tester (HMV-2000; Shimadzu Corporation, Kyoto, Japan). The specimens were individually fixed in the device in such a way that the test surface was perpendicular to the micro-indenter tip. Three indentations (100 g load, $30 \mathrm{~s}$ ) equally spaced over a circle and not closer than $1 \mathrm{~mm}$ to the adjacent indentations or the margin of the specimen were taken and the average was calculated. The post-bleaching measurements were repeated for all the specimens at locations near to the previous series of indentations.

Microhardness of enamel subsurface was obtained after measuring surface microhardness post-bleaching. Specimens were individually included in acrylic resin blocks to facilitate that they were perpendicularly bisected by halves. One crosssectioned face of each specimen was ground and polished following the protocol initially described. Measurements of subsurface microhardness were accomplished at distances of $50 \mu \mathrm{m}, 100 \mu \mathrm{m}, 150 \mu \mathrm{m}$ and $200 \mu \mathrm{m}$ from the external enamel surface. At each distance, three linearly $100-\mu \mathrm{m}-$ spaced indentations were performed and the mean was calculated. Settings for load and penetration were equal to the one employed for surface microhardness.

\section{Statistical Analysis}

Data from color change and microhardness testing were analyzed for homogeneity and normality and were subjected to ANOVA and Tukey's test at a 5\% significance level.

\section{RESULTS}

\section{Color Change}

Table 1 displays the mean values (and standard deviations) of color change ( $\Delta \mathrm{E}^{*}, \Delta \mathrm{L}^{*}, \Delta \mathrm{a}^{*}$, and $\Delta \mathrm{b}^{*}$ values $)$ at each time point. The $\Delta \mathrm{E}^{*}$ values produced by the bleaching agent CP16 were similar to those of CP10, and the $\Delta \mathrm{E}^{*}$ values produced by both $\mathrm{CP} 16$ and $\mathrm{CP} 10$ were significantly superior to those of HP6.5. The $\Delta \mathrm{E}^{*}$ values obtained at each time point revealed that the color changes at 21 days were superior to those observed at 7 days, but similar were similar to those occurred at 14 days. There was no significant difference between 7 and 14 days. The bleaching agents $\mathrm{x}$ time interaction showed that, for CP16, there was no

TABLE 1 - Mean values and standard deviations of $\Delta \mathrm{E}, \Delta \mathrm{L}^{*}, \Delta \mathrm{a}^{*}$, and $\Delta \mathrm{b}^{*}$ according to bleaching time and agent

\begin{tabular}{|c|c|c|c|c|}
\hline & & 7 days & 14 days & 21 days \\
\hline \multirow{3}{*}{$\Delta \mathrm{E}$} & CP10 & $10.22(3.60)$ & $10.72(3.38)$ & 11.63 (3.34) \\
\hline & CP16 & 12.35 (3.16) & $12.92(3.32)$ & $14.05(3.61)$ \\
\hline & HP6.5 & 7.14 (3.22) & $7.51(3.24)$ & 9.37 (3.52) \\
\hline \multirow{3}{*}{$\Delta \mathrm{L}^{*}$} & CP10 & $8.36(4.69)$ & $8.36(4.46)$ & $9.04(4.46)$ \\
\hline & CP16 & $11.75(3.54)$ & $11.27(4.24)$ & $12.39(4.35)$ \\
\hline & HP6.5 & $5.81(3.74)$ & 5.44(3.99) & 7.23(4.58) \\
\hline \multirow[b]{2}{*}{$\Delta \mathrm{a}^{*}$} & CP10 & $0.39(0.82)$ & $0.30(0.72)$ & $0.29(1.05)$ \\
\hline & CP16 & $-0.52(0.87)$ & $-0.68(0.89)$ & $-0.61(0.88)$ \\
\hline \multirow{3}{*}{$\Delta b^{*}$} & CP10 & $-4.54(2.47)$ & $-5.61(2.50)$ & $-6.19(2.73)$ \\
\hline & CP16 & $-3.76(1.51)$ & $-5.49(1.68)$ & $-5.80(2.13)$ \\
\hline & HP6.5 & $-3.57(0.79)$ & $-4.47(1.25)$ & $-4.92(1.97)$ \\
\hline
\end{tabular}


TABLE 2- Mean Knoop microhardness values and standard deviations of enamel surface before and after bleaching treatment with different agents

\begin{tabular}{lll}
\hline Agent & Before bleaching & After bleaching \\
\hline CP10 & $194.58(6.34)$ & $187.08(4.42)$ \\
CP16 & $175.13(5.27)$ & $181.71(5.75)$ \\
HP6.5 & $212.46(3.23)$ & $192.79(3.10)$ \\
\hline
\end{tabular}

spectrophotometers or digital image analysis ${ }^{7,11,28}$.

In the present study, the $16 \%$ carbamide peroxide bleaching agent was more effective than the $10 \%$ carbamide peroxide gel and the strip containing $6.5 \%$ hydrogen peroxide. The reason why $16 \%$ carbamide peroxide gave the highest change in $\mathrm{L}^{*}$ values is probably its extended contact time $(8 \mathrm{~h} /$ day $)$ with enamel compared to the considerably shorter contact time of the $6.5 \%$ hydrogen peroxide gel (30 min twice a day).

It is known that the outcome of a bleaching procedure

TABLE 3- Mean Knoop microhardness values and standard deviations at different distances from enamel surface, before and after bleaching treatment with different agents

\begin{tabular}{ccccc}
\hline Agent & $\mathbf{5 0} \boldsymbol{\mu m}$ & $\mathbf{1 0 0} \boldsymbol{\mu m}$ & $\mathbf{1 5 0} \boldsymbol{\mu m}$ & $\mathbf{2 0 0} \boldsymbol{\mu m}$ \\
\hline CP10 & $176.13(5.10)$ & $184.38(5.62)$ & $183.69(3.53)$ & $179.13(5.51)$ \\
CP16 & $186.09(6.60)$ & $180.59(7.76)$ & $170.59(7.46)$ & $166.80(6.17)$ \\
HP6.5 & $180.45(5.94)$ & $186.00(6.75)$ & $182.15(5.77)$ & $174.86(3.48)$ \\
\hline
\end{tabular}

statistically significant difference between 14 and 21 days. For both CP10 and HP6.5, the $\Delta \mathrm{E}^{*}$ values were statistically significant only at 21 days.

\section{Microhardness Test}

The means and standard deviations of surface microhardness and subsurface microhardness are shown in Table 2 and Table 3, respectively. The analysis of data did not reveal significant differences among the studied factors neither in the surface nor in the subsurface microhardness.

\section{DISCUSSION}

When the objective of an in vitro study is to evaluate the effectiveness of bleaching agents, it is very difficult to observe differences in the effect of bleaching techniques on samples without staining ${ }^{7}$. Thus, the present study used the method proposed by Freccia and Peters ${ }^{8}$ (1982) for artificial staining of extracted teeth. In addition to being reliable, safe and easily reproducible, this method simulates one of the main causes of intrinsic tooth discoloration that is the oxidation of hemoglobin inside dentinal tubules ${ }^{3}$.

A number of methods are available for evaluating the efficacy of bleaching products ${ }^{4}$. Shade guides, photography, colorimeters or computer digitization can be employed to assess tooth color changes ${ }^{20,25,28}$. Tooth color determination employing the commonly cited shade-based guides have limitations as they are subjected to examiner and environmental factors that can potentially influence classification of color ${ }^{9,19}$ and hamper the visualization of color variation existent among the thirds of a tooth crown ${ }^{26}$. The CIEL*a*b* three-dimensional color space system is the most frequently quoted index employed in dental bleaching research and can be generated from colorimeters, depends mainly on the concentration of the bleaching agent, the ability of the agent to reach the chromophore molecules, and the duration and frequency that the agent is in contact with chromophore molecules ${ }^{6}$. Moreover, the difference among the bleaching systems could be explained by the different kinetics of hydrogen peroxide and carbamide peroxide. Hydrogen peroxide acts as a strong oxidizing agent through the formation of free radicals ${ }^{23}$, reactive oxygen molecules, and hydrogen peroxide anions ${ }^{13}$. These reactive molecules attack the long-chained, dark-colored chromophore molecules and split them into smaller, less colored and more diffusible molecules. Carbamide peroxide also yields urea that theoretically can be further decomposed to carbon dioxide and ammonia. The high $\mathrm{pH}$ of ammonia facilitates the bleaching procedure ${ }^{24}$.

The influence of hydrogen peroxide and carbamide peroxide on enamel and dentin properties, such as surface morphology and chemistry, surface and subsurface ultrastructure and microhardness, has been extensively investigated in the literature. According to a recent review ${ }^{16}$, the most frequently employed technique for evaluating the effects of peroxide and bleaching products on enamel and dentin has been surface microhardness. Surface microhardness testing is a simple method for determining the mechanical properties of enamel and dentin surfaces and is related to a loss or gain of mineral of the dental structure ${ }^{16}$. On account of the acidic properties of the bleaching agents, changes in the mineral content of dental hard tissues may occur, leading a decrease in the microhardness values after the bleaching treatment ${ }^{22}$.

However, in the present study, neither the enamel surface microhardness nor the enamel subsurface microhardness was affected by the different bleaching agents employed. As the specimens were maintained in artificial saliva during and after the bleaching treatment, 
it may be assumed that this solution promoted a continuous mineral intake due to the presence of calcium and phosphate ions in its composition, justifying the absence of microhardness changes. This also demonstrates that peroxide bleaching products have no significant effects on microhardness, and contrasting results, in general, reflect some methodological limitations that do not represent the clinical situation or employ highly acidic agents ${ }^{16}$. Furthermore, decrease in microhardness can be recovered in a post-bleaching period, following remineralization from saliva storage ${ }^{21,22}$.

\section{CONCLUSION}

It may be concluded that the $16 \%$ carbamide peroxide gel was the most effective in bleaching stained bovine enamel without causing changes in the microhardness of this substrate.

\section{REFERENCES}

1- Alkhatib MN, Holt R, Bedi R. Prevalence of self-assessed tooth discolouration in the United Kingdom. J Dent. 2004;32:561-6.

2-Al-Salehi SK, Wood DJ, Hatton PV. The effect of 24h non-stop hydrogen peroxide concentration on bovine enamel and dentine mineral content and microhardness. J Dent. 2007;35:845-50.

3- Ari H, Ungör M. In vitro comparison of different types of sodium perborate used for intracoronal bleaching of discoloured teeth. Int Endod J. 2002;35:433-6.

4- Attin T, Schmidlin PR, Wegehaupt F, Wiegand A. Influence of study design on the impact of bleaching agents on dental enamel microhardness: a review. Dent Mater. 2009;25:143-57.

5- Carrasco LD, Guerisoli DM, Rocha MJ, Pécora JD, Fröner IC. Efficacy of intracoronal bleaching techniques with different light activation sources. Int Endod J. 2007;40:204-8.

6- Dahl JE, Pallesen U. Tooth bleaching: a critical review of the biological aspects. Crit Rev Oral Biol Med. 2003;14:292-304.

7- Dietschi D, Rossier S, Krejci I. In vitro colorimetric evaluation of the efficacy of various bleaching methods and products. Quintessence Int. 2006;37:515-26

8- Freccia WF, Peters DD. A technique for staining extracted teeth: a research and teaching aid for bleaching. J Endod. 1982;8:67-9.

9- Gerlach RW, Zhou X. Vital bleaching with whitening strips: summary of clinical research on effectiveness and tolerability. J Contemp Dent Pract. 2001;2:1-16.

10- Götz H, Duschner H, White DJ, Klukowska MA. Effects of elevated hydrogen peroxide 'strip' bleaching on surface and subsurface enamel including subsurface histomorphology, micro-chemical composition and fluorescence changes. J Dent. 2007;35:457-66.

11- Guan YH, Lath DL, Lilley TH, Willmot DR, Marlow I, Brook AH. The measurement of tooth whiteness by image analysis and spectrophotometry: a comparison. J Oral Rehabil. 2005;32:7-15.
12- Hannig C, Lindner D, Attin T. Efficacy and tolerability of two home bleaching systems having different peroxide delivery. Clin Oral Investig. 2007;11:321-9

13- Hannig C, Zech R, Henze E, Dorr-Tolui R, Attin T. Determination of peroxides in saliva: kinetics of peroxide release into saliva during homebleaching with Whitestrips and Vivastyle. Arch Oral Biol. 2003;48:55966

14- Haywood VB, Heymann HO. Nightguard vital bleaching. Quintessence Int. 1989;20:173-6.

15- Heymann HO. Tooth whitening facts and fallacies. Br Dent J. 2005;198:5-14

16- Joiner A. Review of the effects of peroxide on enamel and dentin properties. J Dent. 2007;35:889-96.

17- Joiner A. The bleaching of teeth: a review of the literature. J Dent. 2006;34:412-9.

18- Joiner A. Tooth colour: a review of the literature. J Dent. 2004;32 Suppl 1:3-12.

19- Kugel G, Kastali S. Tooth-whitening efficacy and safety: a randomized and controlled clinical trial. Compend Contin Educ Dent Suppl. 2000;(29):S16-21.

20- Lim MY, Lum SO, Poh RS, Lee GP, Lim KC. An in vitro comparison of the bleaching efficacy of $35 \%$ carbamide peroxide with established intracoronal bleaching agents. Int Endod J. 2004;37:483-8.

21- Maia E, Baratieri LN, Caldeira de Andrada MA, Monteiro S Jr, Vieira LC. The influence of two home-applied bleaching agents on enamel microhardness: an in situ study. J Dent. 2008;36:2-7.

22- Rodrigues JA, Oliveira GP, Amaral CM. Effect of thickener agents on dental enamel microhardness submitted to at-home bleaching. Braz Oral Res. 2007;21:170-5

23- Sulieman M. An overview of bleaching techniques: I. History, chemistry, safety and legal aspects. Dent Update. 2004;31:608-16.

24- Sun G. The role of lasers in cosmetic dentistry. Dent Clin North Am. 2000;44:831-50

25- Vachon C, Vanek P, Friedman S. Internal bleaching with $10 \%$ carbamide peroxide in vitro. Pract Periodontics Aesthet Dent. 1998; 10:1145-52.

26- Watts A, Addy M. Tooth discolouration and staining: a review of the literature. Br Dent J. 2001;190:309-16.

27- Zantner C, Derdilopoulou F, Martus P, Kielbassa AM. Randomized clinical trial on the efficacy of a new bleaching lacquer for self-application. Oper Dent. 2006;31:308-16.

28- Zhang C, Wang X, Kinoshita J, Zhao B, Toko T, Kimura Y, et al. Effects of KTP laser irradiation, diode laser, and LED on tooth bleaching: a comparative study. Photomed Laser Surg. 2007;25:91-5.

29- Ziebolz D, Helms K, Hannig C, Attin T. Efficacy and oral side effects of two highly concentrated tray-based bleaching systems. Clin Oral Investig. 2007;11:267-75. 